[Radiocakbon, Vol. 16, No. 3, 1974, P. 304-306]

\title{
INSTITUT FONDAMENTAL D'AFRIQUE NOIRE RADIOCARBON DATES I
}

\author{
CHEIKH ANTA DIOP
}

\author{
Institut Fondamental d'Afrique Noire, Dakar, Sénégal
}

We follow the same method of radiocarbon dating used in the GifSur-Yvette dating laboratory. Samples are inspected and foreign material removed. Wood and charcoal samples are treated with $0.1 \mathrm{~N}$ ammonium hydroxide and $0.1 \mathrm{~N}$ hydrochloric acid. Shells are treated with $10 \%$ hydrochloric acid to eliminate surface contamination. Bone samples are treated with $0.1 \mathrm{~N}$ ammonium hydroxide to remove humic acids and $10 \% \mathrm{HCl}$ to remove inorganic carbonate and retain collagen for radiocarbon measurements. Sample $\mathrm{CO}_{2}$ is produced by combustion in oxygen. The stream of gases passes over $\mathrm{CuO}$ at $600^{\circ} \mathrm{C}$ to insure complete oxidation of $\mathrm{C}$ to $\mathrm{CO}_{2}$ and through traps containing, respectively, silver nitrate and sulfuric chromic acid solution for purification; barium carbonate is precipited from barium hydroxide bubblers. After filtering and drying, $\mathrm{CO}_{2}$ is liberated from barium carbonate by sulfuric acid. The $\mathrm{CO}_{2}$ is used to fill a 1.2L steel proportional counter at $740 \mathrm{~mm} \mathrm{Hg}$. Age calculations are based on a ${ }^{14} \mathrm{C}$ half-life of $5568 \pm$ yr and 0.95 of activity of the NBS oxalic acid standard; ages are quoted in yr before 1950. Finite ages are quoted with $1 \sigma$ criterion corresponding to the standard deviation based only on counting errors; the maximum age is quoted with 4. $\sigma$ criterion above background.

We sent our results for all samples listed here before receiving data about them. This list includes only cross-check samples from different laboratories; the table summarizes our results. Agreement of dates is generally good; John C Sheppard states that "the disagreements on WSU-1281 and -1302 can be attributed to the high barometric pressure dependence of the WSU system's background."

\section{ACKNOWLEDGMENTS}

I would like to thank Mme Delibrias, Dir, Gif-Sur-Yvette Lab for her help. I would also like to thank M H Barker, British Mus, London, M A Tamers, IVIC, Caracas, Venezuela, and H Tauber, Natl Mus Lab, Copenhagen, Denmark, H E Suess, Univ California, for important information made available to me. I would particularly like to express my gratitude to Le Run, head, Radiocarbon Lab, Gif-Sur-Yvette, during my work there. 


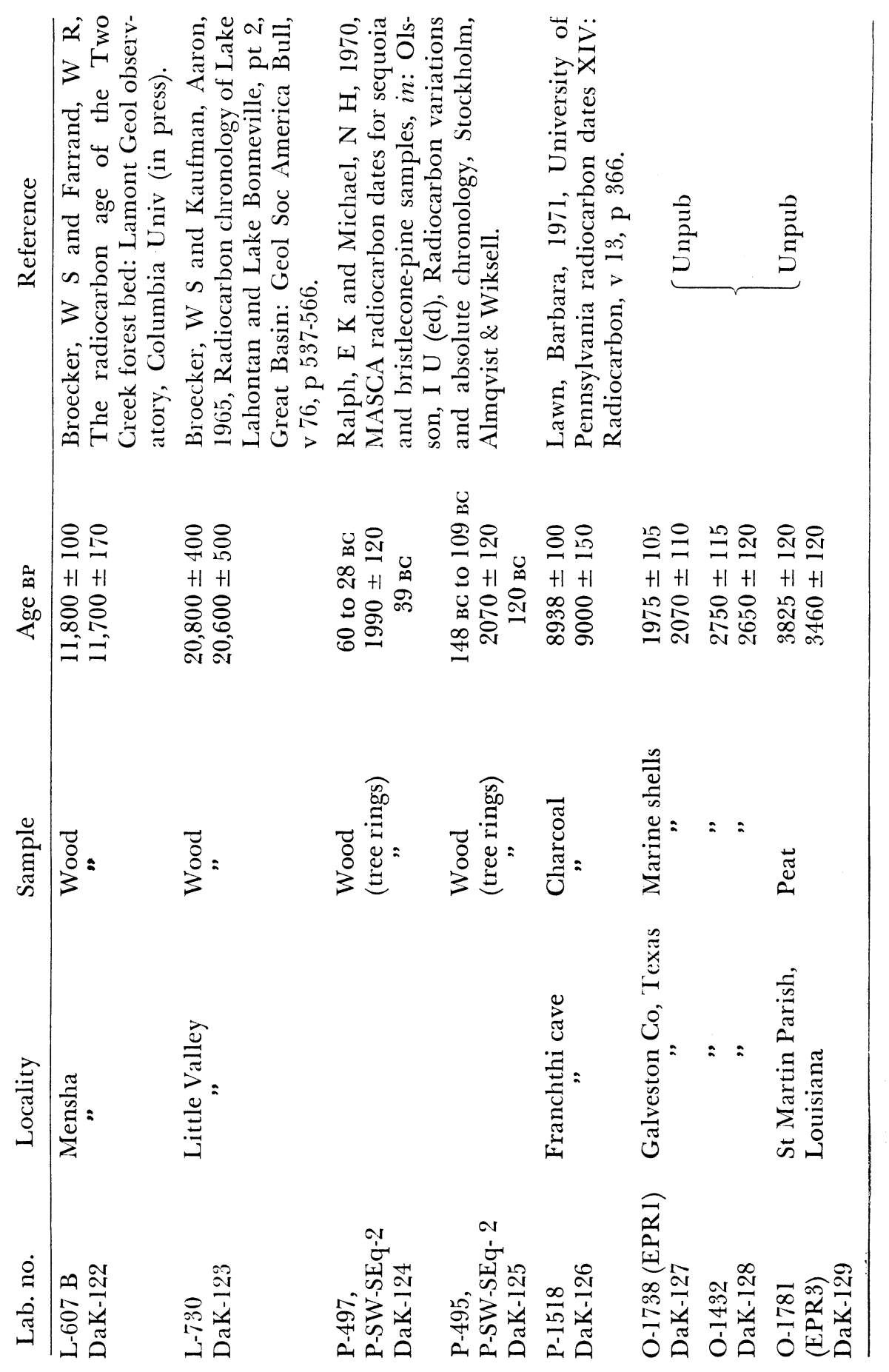


306

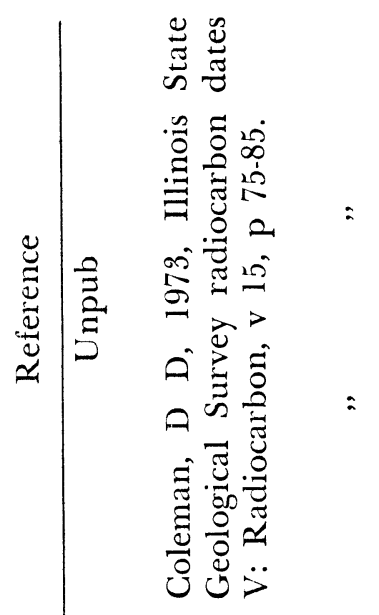

\section{Cheikh Anta Diop}

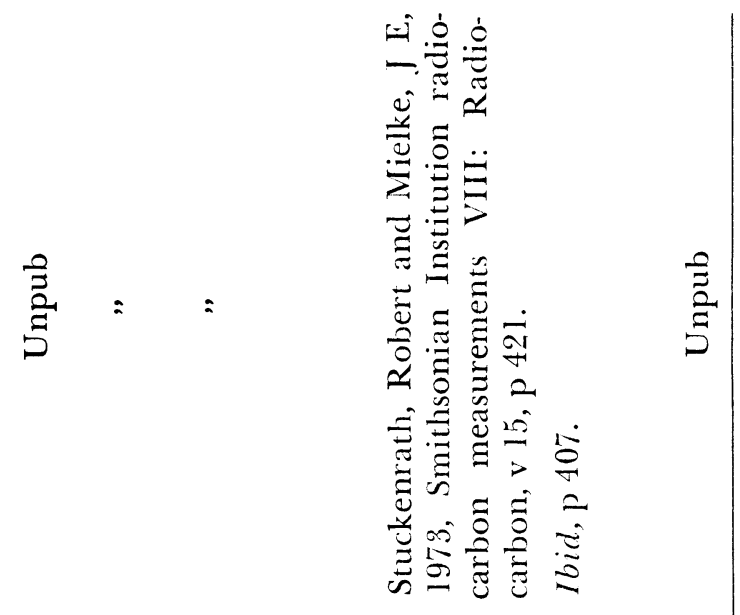

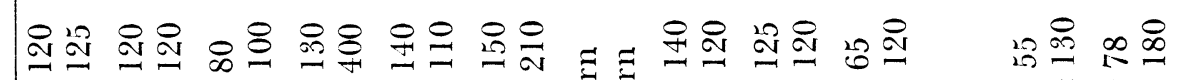

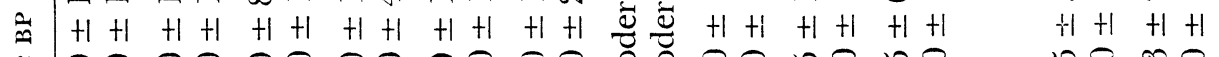

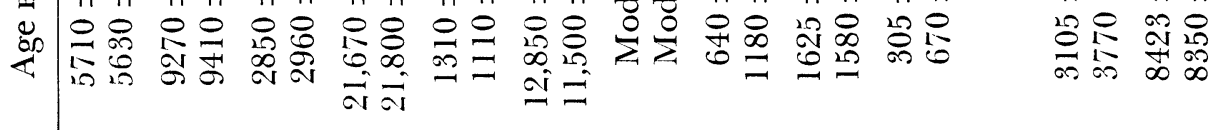

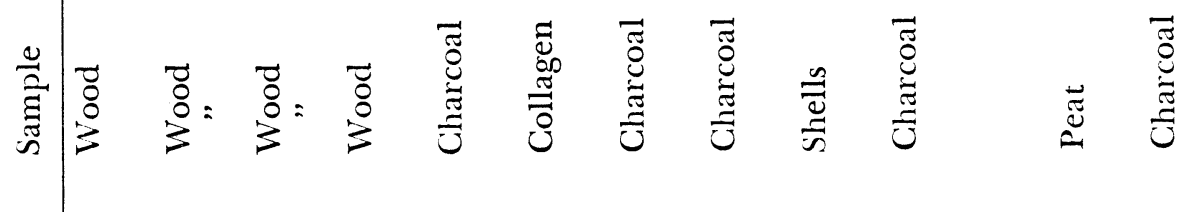

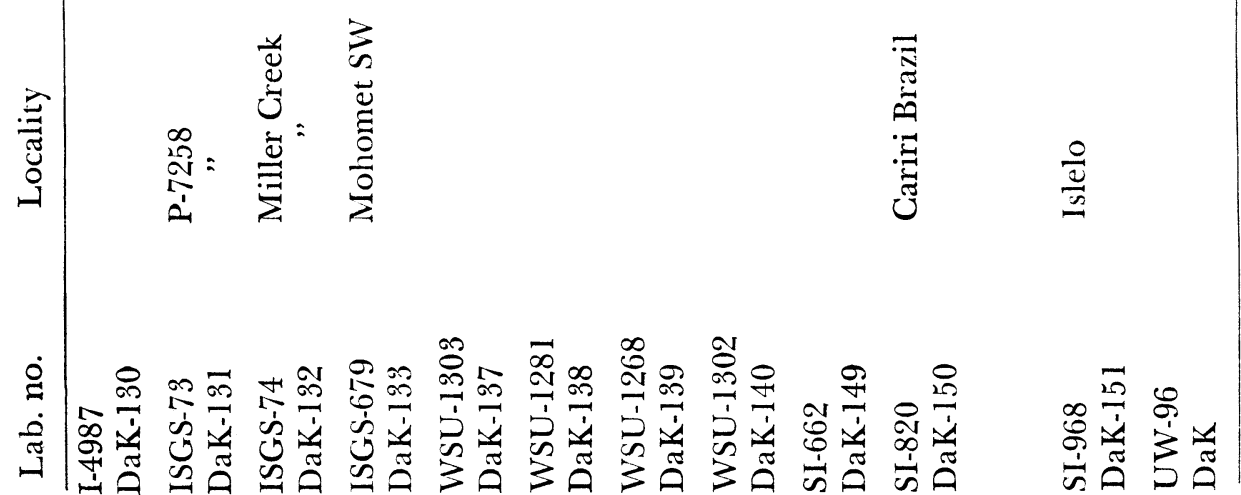

